\title{
Role of Low FODMAP Diet and Probiotics on Gut Microbiome in Irritable Bowel Syndrome (IBS)
}

\author{
Shabnam Mohajir Selvaraj ${ }^{1}$, Sunny Hei Wong ${ }^{2}$, Hooi-Leng Ser ${ }^{1 *}$, Learn-Han Lee ${ }^{1^{*}}$ \\ ${ }^{1}$ Novel Bacteria and Drug Discovery (NBDD) Research Group, Microbiome and Bioresource Research Strength, Jeffrey \\ Cheah School of Medicine and Health Sciences, Monash University Malaysia, 47500 Bandar Sunway, Selangor Darul Ehsan, \\ Malaysia. \\ ${ }^{2}$ Li Ka Shing Institute of Health Sciences, Department of Medicine and Therapeutics, The Chinese University of Hong Kong, \\ Shatin, Hong Kong.
}

\begin{abstract}
Irritable bowel syndrome (IBS) is a chronic disease prevalent in today's society and diet remains the most common aggravator of IBS symptoms. Existing literature suggest that IBS patients are dysbiotic as evidence indicates decreased levels of Bifidobacteria, Bacteroidetes and Faecalibacterium prausnitzii and increased levels of Firmicutes in comparison to healthy individuals. Studies suggest that changes in diet can modulate gut microbiota and therefore improve IBS symptoms. The two diets being investigated are the low FODMAP diet and the use of probiotics. A low FODMAP diet implements a reduction in the amount of poorly absorbed carbohydrates and probiotics are live microorganisms that have been proven beneficial when consumed appropriately. Based on the literature acquired from PubMed, a positive correlation appears to exist between the low FODMAP diet and IBS symptoms; 57\% report symptom relief. There is also a notable effect on the gut microbiome after changing to low FODMAP diet, noted with a significant decrease in levels of Bifidobacterium, Clostridium, F. prausnitzii and Actinobacteria. This poses a concern as bacteria such as Bifidobacteria and F. prausnitzii are beneficial for health. When probiotics are taken amongst IBS patients a reduction in symptoms is also observed. Additionally, there is an increase in the abundance of Bifidobacterium and Lactobacilli. It is suggested that co-administration of probiotics with a low FODMAP diet may ensure beneficial levels of Bifidobacterium while IBS symptoms ameliorate.
\end{abstract}

Keywords: FODMAP; gut microbiome; probiotics; irritable bowel syndrome (IBS).

"Correspondence: Hooi-Leng Ser, Novel Bacteria and Drug
Discovery (NBDD) Research Group, Microbiome and Bioresource
Research Strength, Jeffrey Cheah School of Medicine and
Health Sciences, Monash University Malaysia, 47500 Bandar Sunway,
Selangor Darul Ehsan, Malaysia; ser.hooileng@monash.edu;
hooileng_ser@y7mail.com. Learn-Han Lee, Novel Bacteria and Drug Dis-
overy (NBDD) Research Group, Microbiome and Bioresource Research
Strength, Jeffrey Cheah School of Medicine and Health Sciences,
Monash University Malaysia, 47500 Bandar Sunway, Selangor Darul
Ehsan, Malaysia; lee.learn.han@monash.edu

Received: $10^{\text {th }}$ March 2020

Accepted: $12^{\text {th }}$ April 2020

Published Online: $21^{\text {th }}$ April 2020

Citation: Selvaraj SM, Wong SH, Ser H-L, et al. Role of low FODMAP diet and probiotics on gut microbiome in Irritable Bowel Syndrome (IBS). Prog Microbes Mol Biol 2020; 3(1): a0000069. https://doi.org/10.3687/pmmb.a0000069

\section{Introduction}

Irritable bowel syndrome (IBS) is a functional bowel fact, IBS has a global prevalence of $11 \%$ and accounts for up to $60 \%$ of outpatient appointments in gastroenterology (Figure 1) ${ }^{[1]}$. It is a disease that affects between $10-15 \%$ of individuals in Western countries, while slightly lower rates are seen in Asia, 2.3-11.5\% ${ }^{[2]}$. While the prognosis for this condition is non-fatal, the impact on an individual's quality of life remains significant; IBS patients are 7.93 times more likely to experience severe pain and discomfort, 2.83 times more likely to complain of issues relating to mobility and 2.39 times more likely to disorder and it is more prevalent than one may think. In

experience anxiety and depression ${ }^{[3]}$.

IBS requires an effective and long-term treatment and existing literature has made it abundantly clear that food is a crucial factor correlating with the presentation and severity of gastrointestinal symptoms; $80 \%$ of all IBS patients report being able to identify a minimum of one food item that aggravates their symptoms ${ }^{[4]}$. Furthermore, this disorder is also known to be influenced by a range of factors such as diet, anxiety, gastrointestinal inflammation and family history, thus may require a more holistic approach in its management. The current practice of management of IBS mainly focuses on relief of symptoms such as abdominal pain in combination with dietary modification including the introduction Copyright (C) 2020 by Selvaraj SM and HH Publisher. This work under licensed under the Creative Commons Attribution-NonCommer cial 4.0 International Lisence (CC-BY-NC4.0) 
of low fermentable oligosaccharides, disaccharides, monosaccharides and polyols (FODMAP) diet. On the other hand, some studies have unveiled the relationship between gut microbiome and IBS, suggesting that the imbalance in microbial population may aggravate IBS symptoms ${ }^{[5]}$. Therefore, these evidence then lead to the idea of probiotics intake as a means to reinstate balance in the microbial balance. Probiotics is thought to prevent bacterial overgrowth by improving gut barrier function and receptor interactions, while at the same time producing a range of protective substance include short chain fatty acids (SCFAs $)^{[6]}$. Thus, the directive of the current study aims to provide an overview on the role of gut microbiome in IBS, while consolidating the data on how diet modifications, particularly low FODMAP diet and/or intake of probiotics improve IBS via actions on the gut microbiome.

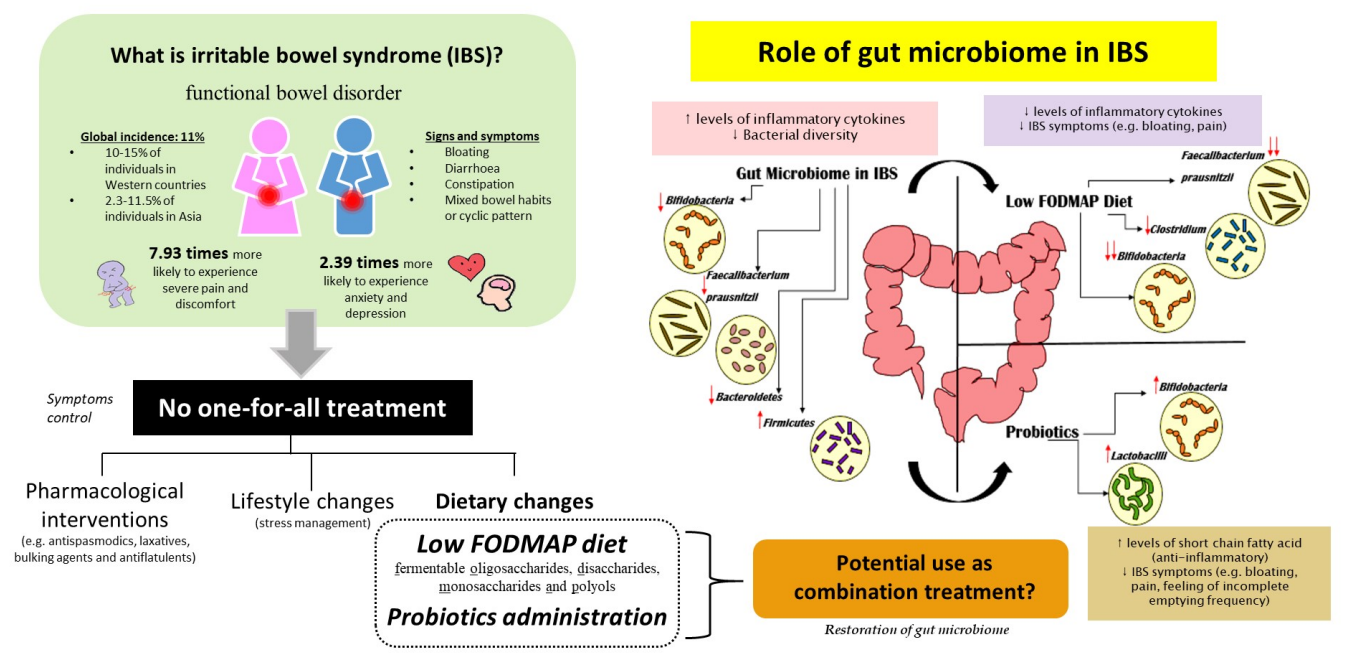

Figure 1: Targeting gut microbiome for the treatment of IBS.

\section{What is irritable bowel syndrome (IBS)?}

As one of the most common functional bowel disorders (FBD), the pathogenesis of IBS remains convoluted. Based on the Rome IV criteria, IBS is defined as a FBD which is distinguished by recurrent abdominal pain accompanied with changes in bowel habits and defecation pattern, in addition to symptoms such as bloating ${ }^{[7]}$. The criteria classifies IBS into subtypes according to the Bristol Stool Scale; IBS with diarrhea (IBS-D), IBS with constipation (IBS-C) and IBS with mixed bowel habits or cyclic pattern (IBS-M) ${ }^{[8]}$. IBS has been associated with a range of intestinal and extra-intestinal presentations; there is often an overlap between the following three conditions-functional dyspepsia, gastroesophageal reflux disease and IBS $^{[9]}$. Urological and gynaecological problems also arise in patients with IBS. On top of the associations made with physical health, mental health has been affected in IBS, with cases of depression and anxiety co-existing. The diagnosis of IBS is commonly suspected through extensive history taking; a pattern of intermittent or continuous abdominal pain, relief with defecation, bloating, flatulence and a lack of alarming features (loss of weight, loss of appetite or an abdominal mass) is suggestive of IBS.

The aetiology of IBS is multifactorial and the pathogenesis of the disease is not fully understood. However, some evidence showed the potential role of gut-brain axis in development of IBS. Known as the"second brain", the huge network of neurons lining the gut forms the enteric nervous system which consists of more than 100 million neuronal cells ${ }^{[10]}$. Evidence suggests that symptoms such as diarrhea and/or pain result from exaggerated responses of the intestine to food or stress and that abnormal mucosal secretions and serotonin uptake by enterocytes cause alterations in gastrointestinal motility ${ }^{[1,12]}$.

Visceral hypersensitivity or pain/discomfort occurs as a result of heightened perception of mechanical triggers applied to the bowel is commonly thought to be the conditions leading to IBS; up to $50 \%$ of patients have been found to have increased visceral perception ${ }^{[13,14]}$. As a matter of fact, gut-brain axis exists as a bidirectional interaction and psychological distress can cause IBS symptoms flareup and exaggeration ${ }^{[15]}$. Besides causing activation in immune system, stress could further enhance dysbiosis or imbalance in the microbial population residing in the gut, which then lead to the development of vicious cycle of inflammation ${ }^{[16-20]}$. Inflammation is another factor in the pathogenesis of IBS as there is increasing evidence of the association between enteric infection and the development of post infectious IBS (PI-IBS) along with studies demonstrating a greater abundance of pro-inflammatory cytokines like IL- $1 \beta$ and IL- 8 in IBS patients ${ }^{[20,21]}$. An eightyear follow up study conducted by Marshall et al. showed that $15.4 \%$ of patients $(n=488)$ were diagnosed with IBS using the Rome I criteria, suggesting an association between enteric infections and persistent IBS symptoms ${ }^{[20]}$. Nevertheless, the study also noted other significant risk factors for the development of PI-IBS such as anxiety and depression, which is in-line with other evidences proposing participation of gut-brain axis in $\operatorname{IBS}^{[21,22]}$. Although the exact mechanism remains unclear, the authors suggested an association between enteric infections and persistent IBS symptoms, particularly caused by prolonged alteration in gut microbiota composition and chronic inflammation.

Above all, the current treatment for IBS patients is mainly to relieve symptoms, whereby the first line management primarily attempts to control diarrhea and constipation along with some over-the-counter medications (e.g. non- 
steroidal anti-inflammatory drugs, anti-flatulent, bulking agent for diarrhea ${ }^{[8,23]}$. On top of that, patients are often advised to change their lifestyles, including stress management and dietary modifications such as high fiber intake, probiotics administration and/or adaptation of a special diet known as the low FODMAP diet. FODMAP refers to a group of carbohydrates, with 1-10 sugars, that are poorly absorbed ${ }^{[24,25]}$. When ingested, they have an osmotic effect; drawing water into the lumen of the small intestine. In the distal ileum and colon, FODMAPs are fermented to produce short-chain fatty acids and gases such as methane, carbon dioxide and hydrogen. Such products of fermentation result in gastrointestinal symptoms in individuals with existing issues of visceral hypersensitivity and gut motility ${ }^{[23,26]}$. Another proposed mechanism through which FODMAPs generate gastrointestinal symptoms is through immune activation. Urinary metabolomic profiles of IBS patients were analysed after low and high FODMAP diets. Such an intervention indicated that patients who took a low FODMAP diet demonstrated a slight decrease in urinary histamine levels. In addition, a decrease in inflammatory cytokines IL-6 and IL- 8 have also been identified in patients undergoing a low FODMAP diet ${ }^{[27,28]}$. Nonetheless, FODMAPs may act as prebiotics, inducing growth and/or activities of bacterial in the gastrointestinal tract thereby changing the composition of the gut microbiome ${ }^{[27,29]}$. So, what is the role of gut microbiome in IBS and more importantly can we tackle the symptoms of this chronic disease by targeting gut microbiome?

\section{Gut Health: IBS and Microbiome}

Out of the 38 trillion bacterial cells living in the human body, more than one-third $(33 \%)$ of them are residing in the gastrointestinal tract ${ }^{[30,31]}$. Gut microbiota has multiple functions and proves beneficial for a range of reasons. For instance, gut microbiome serves like a"physical barrier, preventing colonization by harmful pathogen ${ }^{[32]}$. In reality, gut microbiome was thought to be sterile before birth, but this dogma was challenged numerous times in the past 10 years with studies identifying bacterial DNA and/ or their product present in the placenta, amniotic fluid or even meconium ${ }^{[33]}$. Having said that, the gut microbiome also plays an indispensable role in the development of the immune system; the intestinal mucosa comes in contact with external antigens, presenting antigens and "educating" immune cells on when to attack via binding on receptors (e.g. Toll-like receptor recognition) ${ }^{[32,34]}$. Several observations in rodent models showed that germ free animals (i.e. absence of microbiota) displayed immunological defects with reduced number of immune cells and abnormal functioning ${ }^{[35]}$.

The connection between the gut and health has been well established for centuries; in 400 B.C. Hippocrates stated that death is in the bowels"and implied that indigestion would be the cause of all illnesses. Thousands of years have passed since then and later in 1916, Ali Metchnikoff suggested that diseases originated from the gut, when bad"bacteria can no longer be controlled. The ideal state in gut microbiome or eubiosis is achieved when there is a balance in bacterial abundance, particularly relative abundance of pathogens that may pose serious infectious risk $^{[36]}$. In the gastrointestinal (GI) tract, predominant bacterial phyla comprise of Bacteroidetes and Firmicutes, along with smaller populations of Fusobacteria, Actinobacteria and Verrucomicrobia ${ }^{[37]}$. Typically, the complex microbial community in gut stabilizes after two to three years of age ${ }^{[38]}$. Nevertheless, it should be highlighted that variations exist between individuals as a multitude of factors contribute to the microbial composition such as age and diet to name a few ${ }^{[37,39,40]}$.

Dysbiosis in the gut microbiome has been suggested to be associated with a combination of both acute and chronic diseases, or, increase the risk of its development. The different potential mechanisms on how dysbiosis and/or certain metabolites can lead to mucosal leakiness in the gut and promote inflammation milleu in entire body has been actively conversed over the past ten years ${ }^{[41-46]}$. In the recent years, many researchers have witnessed the changes in gut microbiome and its relationship to the pathogenesis of illnesses, particularly in those with $\operatorname{IBS}^{[30,47-51]}$. In patients with PI-IBS, it is simply obvious that those with history of enteric infection have a higher risk of developing IBS, given that the abundance of microbial population in the gut changed with the colonization of pathogens ${ }^{[51,52]}$. These patients have been shown to have decreased levels of Bifidobacteria, Bacteroidetes and F. prausnitzii and an increase in the abundance of Firmicutes. A 2-fold decrease in Bifidobacteria is found in IBS patients compared to healthy controls; Bifidobacteria is beneficial to the host as it produces acetic and lactic acid, thereby preventing the growth of pathogenic bacteria and maintaining the immune system $^{[52-54]}$.

Apart from the differences in microbial taxa, studies have also suggested a reduction in microbial diversity, richness and temporal stability. Tap et al. found that the severity of IBS symptoms is negatively associated with microbial richness and enterotypes enriched with Clostridiales/Prevotella species $^{[55]}$. This was further emphasized by Halkjaer et al. whereby IBS patients have a lower stool microbial biodiversity, suggesting an association between IBS and gut microbiome ${ }^{[56]}$. In conjunction with this, there are some studies suggest that microbial composition varies according to IBS subtypes. In a study conducted by Jeffery and team, Lactobacilli was found in greater abundance in IBS-D patients in comparison to IBS-C patients ${ }^{[52]}$. Additionally, the luminal microbiota of patients with PI-IBS was distinguishable from non-PI-IBS patients, but like those with IBS-D. Furthermore, Kroguis-Kirikk et al. found a reduction in microbial diversity in IBS-D patients and this can be related to the reduction in microbial composition identified in patients with acute diarrhea ${ }^{[57]}$. Conversely, similar results were obtained in animal models of IBS, whereby fecal transplantation using stool from IBS patients induced visceral hypersensitivity in germ-free rats ${ }^{[58]}$.

\section{Relationship between Low FODMAP Diet and Gut Microbiome}

Following the diagnosis of IBS, dietary changes are often crucial steps to control unwanted symptoms such as diarrhea and bloating. The traditional IBS diet focuses a great deal on when and how to eat. Commonly, patients are told to eat 3 meals and 3 snacks a day and to reduce their intake of foods such as coffee, fatty foods, alcohol and spicy dishes ${ }^{[59]}$. Along with that, since the knowledge of saccharides causes 
gastrointestinal symptoms came to light, IBS patients are introduced to a meal plan"with low composition of FODMAP content as these are considered potential triggers $^{[25,30]}$. In a low FODMAP diet, the daily intake of FODMAPs in an IBS patient is reduced from $15-30 \mathrm{~g} / \mathrm{d}$ to $5-18 \mathrm{~g} / \mathrm{d}$. The execution of this diet requires global restriction for 4-8 weeks followed by reintroduction of food according to a patient's tolerance. As a consequence, this diet is not only "therapeutic" food avoidance plan but can also use as a diagnostic tool to test food intolerance.

The low FODMAP diet can be deemed clinically effective as a total of $50-70 \%$ of patients with IBS reported adequate symptom relief, marked by a lower IBS symptom severity score after implementing a low FODMAP $\operatorname{diet}^{[1,27,60]}$. Evidence suggests that gastrointestinal symptoms ameliorate, with reported reductions in bloating, borborygmi, stool frequency, urgency and improvement in consistency ${ }^{[1,59,61]}$. Taking a closer look at the microbial composition, Hustoft et al. indicated that reduction in FODMAP intake (50\%) produced a significant change in microbial composition; a 6-fold reduction was observed in those following low FODMAP diet in the relative abundance of Bifidobacteria, in comparison to individuals on normal diet (Table 1) ${ }^{[28]}$. Similarly, Silk et al. found that a significant reduction in Bifidobacteria abundance was seen following a 3-week implementation of a low FODMAP diet. Differing from Histoft et al., this study also found a $47 \%$ overall reduction in total bacterial count and a reduction in abundance of other bacterial groups ${ }^{[62]}$. A significant reduction was found in Clostridium, F. prausnitzii, Bifidobacterium, Megasphaera,Pediococcus and Actinobacteria and patients presented more dysbiotic gut microbiome. Likewise, a study by McIntosh et al. highlighted an increase in the relative abundance of bacteria involved in gas consumption in patients on low FODMAP $\operatorname{diet}^{[27]}$. Members of genus Adlercreutzia are described as hydrogen "consumers" for equol production, while reducing gas formation and eventually preventing symptoms of bloating and pain simultaneously ${ }^{[27,63]}$.

Table 1. Effect of low FODMAP diet on IBS symptoms and gut microbiota.

\begin{tabular}{|c|c|c|c|}
\hline Study Design & Methods & Impact of Low FODMAP Diet on IBS symptoms & References \\
\hline $\begin{array}{l}\text { Randomised Con- } \\
\text { trolled Trial }\end{array}$ & $\begin{array}{l}\text { IBS Symptom Scoring } \\
\text { System (IBS-SSS) }\end{array}$ & $\begin{array}{l}57 \% \text { had adequate pain relief vs control }(38 \%) \\
73 \% \text { achieved }>50 \text { reduction of IBS-SSS score vs control } \\
\text { No significant difference for IBS-QOL }\end{array}$ & {$[61]$} \\
\hline $\begin{array}{l}\text { Randomised Con- } \\
\text { trolled Trial }\end{array}$ & $\begin{array}{l}\text { IBS Symptom Scoring } \\
\text { System (IBS-SSS) }\end{array}$ & $\begin{array}{l}\text { Mean decrease of } 28 \% \text { vs. control } \\
\text { High FODMAP group had a mean increase of } 7 \% \text { in symptoms } \\
52 \% \text { reduction in abdominal pain } \\
\text { Positive correlation between IBS symptom severity and level of FODMAP } \\
\text { consumption }\end{array}$ & {$[27]$} \\
\hline $\begin{array}{l}\text { Randomised Con- } \\
\text { trolled Trial }\end{array}$ & $\begin{array}{l}\text { IBS Symptom Scoring } \\
\text { System (IBS-SSS) }\end{array}$ & $\begin{array}{l}\text { Symptom severity was reduced in both groups } \\
\text { There was no significant difference between the IBS-SSS scores in both groups } \\
\text { compared to baseline. } \\
\text { The number of bowel movements reduced in the low FODMAP group compared to the } \\
\text { traditional diet group. }\end{array}$ & {$[59]$} \\
\hline Study Design & Methods & Impact of Low FODMAP Diet on Gut Microbiota & References \\
\hline $\begin{array}{l}\text { Randomised Con- } \\
\text { trolled Trial }\end{array}$ & $16 \mathrm{~S}$ rRNA & $\begin{array}{l}\text { Increase in the number of dysbiotic patients after the low FODMAP diet (60\%) } \\
\text { Reduction in Clostridium, Faecalibacterium prausnizii, Bifidobacterium, Megasphaera, } \\
\text { Pediococcus and Actinobacteria. }\end{array}$ & {$[28]$} \\
\hline $\begin{array}{l}\text { Randomised } \\
\text { Cross Over Con- } \\
\text { trolled Trial }\end{array}$ & FISH & $\begin{array}{l}\text { No difference in the relative proportion of each bacterial group at baseline and post } \\
\text { intervention. } \\
\text { Higher proportions of Bifidobacterium spp. } \\
\text { Lower proportions of } C \text {. perfingens subgroup histolyticum and Bacteroides/Prevotella } \\
\text { spp. }\end{array}$ & {$[62]$} \\
\hline $\begin{array}{l}\text { Randomised Con- } \\
\text { trolled Trial }\end{array}$ & $\begin{array}{l}16 \mathrm{~S} \text { rRNA } \\
\text { Operational Taxonomic } \\
\text { Units (OTU) }\end{array}$ & $\begin{array}{l}\text { No difference between a-diversity or } \beta \text {-diversity. } \\
\text { Higher Actinobacteria richness and diversity } \\
\text { IBS-M and IBS-D had higher bacterial richness (Firmicutes, Clostridiales and } \\
\text { Actinobacteria). } \\
\text { Actinobacteria } \text { richness was increased }\end{array}$ & {$[27]$} \\
\hline $\begin{array}{l}\text { Randomised Con- } \\
\text { trolled Trial }\end{array}$ & 16S rRNA & $\begin{array}{l}\text { Responders had high levels of: Bacteroidaceae, Clostridiales (Ruminococcaceae, } \\
\text { Dorea and Faecalibacterum prausnitzii) and Erysipilotrichaceae }\end{array}$ & {$[64]$} \\
\hline $\begin{array}{l}\text { Randomised Con- } \\
\text { trolled Trial }\end{array}$ & GA-map ${ }^{\mathrm{TM}}$ Dysbiosis Test & $\begin{array}{l}\text { Responders has a high level of: Bacteriodes fragilis, Acinetobacter, Ruminiclostridium, } \\
\text { Streptococcus and Eubacterium. } \\
\text { Responders had lower levels of: Clostridials, Shigella/Escherichia, Unable to identify a } \\
\text { significant change in dysbiosis. }\end{array}$ & {$[65]$} \\
\hline
\end{tabular}


Even so, some researchers argued that the effectiveness of the low FODMAP diet may be dependent upon individual gut microbial composition. Chumpitazi et al. conducted a study among children and concluded that $24 \%$ of patients who experienced symptom response had a high abundance of Bacteroides, Ruminococcaceae and $F$. prausnitzii ${ }^{[64]}$. These findings therefore proposed that the greatest benefit of a low FODMAP diet can be seen in patients who have a high concentration of microbiota with saccharolytic potential. Amongst adults, patients who respond significantly to the diet have been found to have higher levels of Bacteroides fragilis, Acinetobacter, Ruminiclostridium, Streptococcus and Eubacterium ${ }^{[65]}$.

\section{Administration of Probiotics in IBS Patients}

In IBS patients, several studies have indicated a drop in abundance of certain beneficial microbes or probiotics, particularly those under the phyla Bifidobacterium and Actinobacteria ${ }^{[51,52,66]}$. Besides producing lactic acid from digested dietary sugars, some probiotics such as Lactobacillus, Lactococcus, Bifidobacterium and Streptococcus are capable of producing small chain fatty acids (SCFAs) like butyrate, propionate and acetate through fermentation of ingested food ${ }^{[67]}$. SCFAs, in particular butyrate is the primary energy source for colon cells and plays a central role in intestinal maintenance through antiinflammatory actions ${ }^{[68-71]}$. In addition to that, one of the most traditional theory on how probiotics confer protection to the host is by displacing pathogenic GI bacteria, preventing their colonization and subsequently re-establishing the balance in gut microbiome.

In the light of current research on IBS, many researchers have reported the benefits of probiotics in IBS patients, particularly in the reduction of IBS symptoms such as abdominal pain and bloating ${ }^{[72-76]}$. A multicenter studies conducted in India by Ducrotte and team showed that $78.1 \%$ of patients consider treatment with Lactobacillus plantarum $299 \mathrm{v}$ to be effective (Table 2) ${ }^{[73]}$.

Table 2. The effect of probiotics on IBS symptoms and gut microbiota.

\begin{tabular}{|c|c|c|c|c|c|c|}
\hline \multirow[t]{2}{*}{ Study Design } & \multicolumn{2}{|l|}{ Methods } & \multirow{2}{*}{$\begin{array}{l}\text { Probiotics intervention } \\
\text { (Form: single/multi-strains; } \\
\text { Dose; Duration) }\end{array}$} & \multirow{2}{*}{\multicolumn{2}{|c|}{$\begin{array}{l}\text { Impact of Probiotics on Gut } \\
\text { Microbiota }\end{array}$}} & \multirow[t]{2}{*}{ References } \\
\hline & $\begin{array}{l}\text { Monitoring IBS } \\
\text { symptoms and } \\
\text { quality of life }\end{array}$ & $\begin{array}{l}\text { Monitoring of } \\
\text { microbiome }\end{array}$ & & & & \\
\hline $\begin{array}{l}\text { Randomised } \\
\text { Controlled } \\
\text { Trial }\end{array}$ & $\begin{array}{l}\text { Patient Diary; } \\
\text { RAND-36 }\end{array}$ & N.R. & $\begin{array}{l}\text { Capsule: L. rhamnosus GG, } L \text {. } \\
\text { rhamnosus LC705, } B . \\
\text { breve } \mathrm{Bb} 99 \text { and } P \text {. freuden- } \\
\text { reichii } \mathrm{ssp} \text {. shermanii JS (Valio } \\
\text { Ltd, Helsinki, Finland. } \\
\text { Equal amount of strain: each } \\
8-9 \times 10^{9} \mathrm{CFU} / \text { day } \\
\text { Duration: } 6 \text { months }\end{array}$ & $\begin{array}{l}\text { a. } \\
\text { b. } \\
\text { c. }\end{array}$ & $\begin{array}{l}42 \% \text { reduction in } \\
\text { symptom score } \\
\text { Probiotics appeared to be } \\
\text { beneficial for all } \\
\text { symptoms. } \\
\text { Significant reduction in } \\
\text { scores for borborygmi }\end{array}$ & [78] \\
\hline $\begin{array}{l}\text { Randomised } \\
\text { Controlled } \\
\text { Trial }\end{array}$ & $\begin{array}{l}\text { Patient Diary; } \\
\text { RAND-36 }\end{array}$ & $\begin{array}{l}\text { Human Intesti- } \\
\text { nal Tract chip } \\
\text { (HITChip, Agilent } \\
\text { Technologies) }\end{array}$ & $\begin{array}{l}\text { Drink: L. rhamnosus GG } \\
\text { (ATCC 53103, LGG (Valio Ltd, } \\
\text { Helsinki, Finland)), L. rham- } \\
\text { nosus Lc705 (DSM 7061), P. } \\
\text { freudenreichii ssp. sherma- } \\
\text { nii JS (DSM 7067) and B. } \\
\text { animalis ssp. lactis Bb12 (DSM } \\
\text { 15954) } \\
\text { Equal amount of strain: each } \\
1 \times 10^{7} \text { CFU/mL } \\
\text { Duration: } 5 \text { months }\end{array}$ & a. & $\begin{array}{l}\text { Higher mean reduction in } \\
\text { IBS score in the probiotic } \\
\text { group, recorded at } 37 \% \text {, } \\
\text { compared to only } 9 \% \\
\text { reduction in the placebo } \\
\text { group } \\
\text { Health-related quality } \\
\text { of life analysis showed } \\
\text { improvement in the } \\
\text { probiotic group for the } \\
\text { domain describing bowel } \\
\text { symptoms }\end{array}$ & {$[72]$} \\
\hline $\begin{array}{l}\text { Randomised } \\
\text { Controlled } \\
\text { Trial }\end{array}$ & $\begin{array}{l}\text { Visual Analogue } \\
\text { Scale (VAS) }\end{array}$ & N.R. & $\begin{array}{l}\text { Capsule: L. plantarum 299v } \\
\text { (DSM 9843) } \\
\text { Amount: } 1 \times 10^{10} \mathrm{CFU} / \text { day } \\
\text { Duration: } 4 \text { weeks }\end{array}$ & $\begin{array}{l}\text { a. } \\
\text { b. } \\
\text { c. }\end{array}$ & $\begin{array}{l}45.2 \% \text { reduction in mean } \\
\text { severity of abdominal } \\
\text { pain. } \\
78.1 \% \text { found the treat- } \\
\text { ment good/excellent } \\
\text { compared to placebo } \\
(8.1 \%) \\
\text { No significant side ef- } \\
\text { fects }\end{array}$ & [73] \\
\hline $\begin{array}{l}\text { Randomised } \\
\text { Controlled } \\
\text { Trial }\end{array}$ & N.R. & $\begin{array}{l}\text { qPCR (Selected } \\
\text { bacterial group } \\
\text { only) }\end{array}$ & $\begin{array}{l}\text { Capsule: L. rhamnosus GG } \\
\text { (ATCC 53103), L. rhamno- } \\
\text { sus Lc705 (DSM 7061), P. } \\
\text { freudenreichii ssp. shermanii JS } \\
\text { (DSM 7067) and B. breve Bb99 } \\
\text { (DSM 13692) } \\
\text { Equal amount of strain: each } \\
8-9 \times 10^{9} \text { CFU/day } \\
\text { Duration: } 6 \text { months }\end{array}$ & & $\begin{array}{l}\text { Intestinal microbiota } \\
\text { remained stable except } \\
\text { for Bifidobacterium spp. } \\
\text { Number of } \\
\text { Bifidobacterium spp } \\
\text { decreased }\end{array}$ & [76] \\
\hline
\end{tabular}




\begin{tabular}{|c|c|c|c|c|c|c|}
\hline $\begin{array}{l}\text { Randomised } \\
\text { Controlled } \\
\text { Trial }\end{array}$ & $\begin{array}{l}\text { Clinical assessment } \\
\text { at baseline and end } \\
\text { of treatment } \\
\text { Telephone inter- } \\
\text { view (1 month after } \\
\text { end of treatment) }\end{array}$ & qPCR & $\begin{array}{l}\text { VSL- } 3 \text { : } 9.3 \times 10^{10} \mathrm{CFU} / \mathrm{g} \text { of Bi- } \\
\text { fidobacterium }(\text { B. longum } \mathrm{Y} 10 \text {, } \\
\text { B. infantis } \mathrm{Y} 1 \text { and } B . \text { breve } \mathrm{Y} 8 \text {, } \\
2.7 \times 10^{9} \mathrm{CFU} / \mathrm{g} \text { of Lactobacil- } \\
\text { lus }(\text { L. acidophilus, L. casei, L. } \\
\text { delbrueckii subsp. bulgaricus } \\
\text { and L. plantarum }) \text { and } 2 \times 10^{11} \\
\text { CFU } / \mathrm{g} \text { of Streptococcus salivar- } \\
\text { ius subsp. thermophilus. } \\
\text { Duration: } 20 \text { days }\end{array}$ & b. & $\begin{array}{l}\text { Significant increase in } \\
\text { Lactobacilli, Bifidobac- } \\
\text { teria } \text { and Streptococcus } \\
\text { thermophilus } \\
\\
\text { No significant changes in } \\
\text { enterococci, coliforms, } \\
\text { Bacteroides and Clos- } \\
\text { tridium perfingens. }\end{array}$ & [82] \\
\hline $\begin{array}{l}\text { Randomised } \\
\text { Controlled } \\
\text { Trial }\end{array}$ & N.A. & $\begin{array}{l}\text { qPCR (Selected } \\
\text { bacterial group } \\
\text { only) }\end{array}$ & $\begin{array}{l}\text { Capsule: Lactobacillus } \\
\text { rhamnosus GG, L. rhamno- } \\
\text { sus Lc705, Propionibacterium } \\
\text { freudenreichii sp. shermanii JS } \\
\text { and Bifidobacterium breve Bb99 } \\
\\
\text { Equal amount of strain: each } \\
8-9 \times 10^{9} \text { CFU/day } \\
\text { Duration: } 6 \text { months }\end{array}$ & b. & $\begin{array}{l}\text { Group receiving pro- } \\
\text { biotics appeared to be } \\
\text { display lesser monitored } \\
\text { IBS-related GI symp- } \\
\text { toms. } \\
\text { Significant decrease in } \\
\text { the amount of } R \text {. torques } \\
94 \% \text {, increase in } C \text {. ther- } \\
\text { mosuccinogenes } 85 \% \text {. } \\
\text { Increased abundance of } \\
\text { Ruminococcus torques } \\
93 \% \text {. } \\
\text { Bifidobacterium de- } \\
\text { creased in the probiotic } \\
\text { group }\end{array}$ & [79] \\
\hline
\end{tabular}

IBS patients reported overall reductions in stool frequency, bloating and feeling of incomplete emptying frequency after 4-weeks administration of probiotics. Furthermore, there are studies emphasized that multi-strain probiotics have shown a more significant impact on improving gastrointestinal symptoms as compared to single strain probiotics. This is likely due to the fact that more niches are colonized, thus having a greater effect on gut motility ${ }^{[76,77]}$. A study using a probiotic mixture containing Lactobacillus rhamnosus GG, L. rhamnosus LC705, Bifidobacterium breve Bb99 and Propionibacterium freudenreichii sp. shermanii revealed that IBS patients experienced lesser symptoms, achieving a reduction rate as high as $42 \%$ in symptom score, whereas the placebo group only reported a $6 \%$ reduction ${ }^{[78]}$. Also, the gut microbiome of IBS patient receiving probiotics was indeed different compared to the placebo as examined using similarity index which compared the stability of the microbiota composition at baseline and post-intervention. Similar observation was obtained by Lyra and team where they observed that probiotics intake reduced amount of Ruminococcus torques $94 \%$, which has been associated with gastrointestinal diseases like Crohn's Disease as well as IBS ${ }^{[79-81]}$.

After all these years, the use of probiotics in IBS remains as a compelling topic as some studies did not produce obvious long-term efficacy compared to placebo. For instance, using another commercially available probiotics capsule, VSL-3 which contains Bifidobacterium, Lactobacillus, Streptococcus salivarius subsp. thermophiles, Brigidi and team observed an increase in these probiotics, but not other bacterial population such as enterococci, coliforms, Clostridium perfringens and Bacteroides $^{[82]}$. The same team also noted that the gut microbial composition returned to initial values once the probiotic had been suspended, indicating that the effects do not persist long term. However, bearing in mind that most of the previous studies investigated these using conventional qPCR targeting genes like 16S-23S ribosomal RNA may not provide a full glimpse of which population changes after intervention. Additionally, most studies have also highlighted that patients can continue with their normal diet, regardless of whether they are taking probiotics or placebo, which may explain for the inconsistencies in data. There are some concerns over the form of probiotics used such as capsule, liquid or powdered form, as studies have pointed out that the delivery systems vary greatly in effectiveness ${ }^{[83]}$. Nonetheless, with the advancement in next generation sequencing and enhanced computational power, it may be easier to visualize how gut microbiome changes after probiotics intake in IBS patients, and at the same time answer the doubts on whether the observed effect is due to specific strains or a synergistic effect of these probiotics. Consequently, this method would also assist the development of biomarkers to facilitate the detection and/or diagnosis of IBS on top of classic clinical assessment.

\section{Conclusion and Future Recommendations}

It is evident that gut microbiome plays an important role in maintenance of gut health, including IBS. Even though some medications may alleviate symptoms for IBS patients, there is still no one-for-all drug or treatment plan that would work for all of them ${ }^{[59,60]}$. The low FODMAP diet has shown to be one of the clinically effective strategy by reducing overall symptom severity in multiple studies. By adhering to the low FODMAP diet, patients may not experience symptoms flare-up but it is a challenging diet to adopt in certain regions of the world, particularly limitation of food choices as well as insufficient knowledge in delivery of the diet plan among medical practitioners ${ }^{[84,85]}$. Some clinicians may doubt its implementation in the long run as a significant reduction in carbohydrates, iron and fiber can lead to other issues like calcium deficiency. While this may be concerning, concurrent use of probiotics along with 
low FODMAP diet may really help to ensure beneficial levels of Bifidobacteria are maintained. Theoretically, the gut microbiome patients receiving probiotics could make up for the reduced diversity following the restrictive diet, particularly by increasing the abundances of these probiotics $^{[1,76,77]}$. In actual fact, there are still much to do before researchers could unravel the role of gut microbiome or even specific microbial population in IBS. Amongst existing studies, there is a lack of consistency and clarity which may be attributed by the heterogeneity between them. This heterogeneity exists in variations in individual baseline microbiota, potential microbial differences according to the IBS subtypes, study designs, the methods of analyzing the microbiota composition, the definition of clinical response and the population of selected individuals for the study ${ }^{[4,52]}$. Above and all, an innovative approach like combining probiotics and low FODMAP diet in combating IBS is clinically applicable with no or minimal side effects. Further investigations incorporating high throughput next generation sequencing technologies, analytical tools like chromatography and mass spectrometry techniques as well as improvement in delivery methods of probiotics may expedite the development of the next effective regime for the management of IBS.

\section{Conflict of Interest}

The authors declare that there is no conflict of interest in this work.

\section{Author Contributions}

The literature review and manuscript writing were performed by SMS and H-LS. SHW and L-HL provided vital guidance of the research and proof of the writing. L-HL and H-LS founded the research project.

\section{References}

1. Staudacher HM, Lomer MC, Farquharson FM, et al. A diet low in FODMAPs reduces symptoms in patients with irritable bowel syndrome and a probiotic restores Bifidobacterium species: A randomized controlled trial. Gastroenterol 2017; 153(4): 936-947.

2. Chang F, Lu C, Chen T. The current prevalence of irritable bowel syndrome in Asia. J Neurogastroenterol Motil 2010; 16: 389-400. doi:10.5056/jnm.2010.16.4.389.

3. Wang Y, Lim H, Tai D, et al. The impact of irritable bowel syndrome on health-related quality of life: A Singapore perspective. BMC Gastroenterol 2012; 12. doi: 10.1186/1471-230x-12-104.

4. Chumpitazi B. The gut microbiome as a predictor of low fermentable oligosaccharides disaccharides monosaccharides and polyols diet efficacy in functional bowel disorders. Curr Op Gastroenterol 2019; 1. doi:10.1097/mog.0000000000000608

5. Menees S, Chey W. The gut microbiome and irritable bowel syndrome. F1000Res 2018;7. doi: 10.12688/f1000research.14592.1.

6. Cremon C, Barbaro MR, Ventura M, et al. Pre-and probiotic overview. Curr Op Pharmacol 2018; 43: 87-92.

7. Lacy B, Patel N. Rome criteria and a diagnostic approach to irritable bowel syndrome. J Clin Med 2017; 6: 99. doi: 10.3390/jcm6110099.

8. Quigley E, Fried M, Gwee K, et al. World gastroenterology organisation global guidelines irritable bowel syndrome. J Clin Gastroenterol 2016; 50: 704-713. doi: $10.1097 / \mathrm{mcg} .0000000000000653$.

9. Quigley E. Changing face of irritable bowel syndrome. World J Gastroenterol 2006; 12: 1. doi:10.3748/wjg.v12.i1.1.

10. Furness JB, Callaghan BP, Rivera LR, et al. The enteric nervous system and gastrointestinal innervation: Integrated local and central control. Adv Exp Med Biol 2014; 817: 39-71. doi: 10.1007/978-1-4939-0897-4 3 .

11. Gunnarsson J, Simrén M. Peripheral factors in the pathophysiology of irritable bowel syndrome. Dig Liver Dis 2009; 41(11): 788-793. doi: 10.1016/j.dld.2009.07.006.

12. Staudacher H, Whelan K. Altered gastrointestinal microbiota in irritable bowel syndrome and its modification by diet: Probiotics, prebiotics and the low FODMAP diet. Proc Nut Soc 2016; 75: 306-318. doi: 10.1017/ s0029665116000021

13. Ritchie J. Pain from distension of the pelvic colon by inflating a balloon in the irritable colon syndrome. Gut 1973;14(2): 125-132. doi:10.1136/ gut.14.2.125

14. Hungin A, Becher A, Cayley B, et al. Irritable bowe syndrome: An integrated explanatory model for clinical practice. Neurogastroenterol Motil 2015; 27 (6): 750-763. doi: $10.1111 / \mathrm{nmo} .12524$

15. Qin HY, Cheng CW, Tang XD, et al. Impact of psychological stress on irritable bowel syndrome. World J Gastroenterol 2014; 20(39): 14126 14131 .

16. Matricon J. Commentary: Associations between immune activation, intestinal permeability and irritable bowel syndrome - author's reply. Aliment Pharmacol Ther 2012; 37(2): 278-279. doi: 10.1111/apt.12150.

17. Lee LH, Ser HL, Khan TM, et al. IDDF2018-ABS-0239 Dissecting the gut and brain: Potential links between gut microbiota in development of Alzheimer's disease? Gut 2018; 67: A18.

18. Lee LH, Ser HL, Khan TM, et al. IDDF2019-ABS-0321 Relationship between autism and gut microbiome: Current status and update. Gut 2019; 68: A40-A41.

19. Li N, Wang Q, Wang Y, et al. Oral probiotics ameliorate the behaviora deficits induced by chronic mild stress in mice via the gut microbiotainflammation axis. Front Behav Neurosci 2018; 12: 266.

20. Gwee KA, Collins SM, Read NW, et al. Increased rectal mucosal expression of interleukin $1 \beta$ in recently acquired post-infectious irritable bowel syndrome. Gut 2003; 52(4): 523-526.

21. Marshall J, Thabane M, Garg A, et al. Eight year prognosis of postinfectious irritable bowel syndrome following waterborne bacterial dysentery. Gut 2010; 59(5): 605-611. doi: 10.1136/gut.2009.202234

22. Dunlop SP, Jenkins $\mathrm{D}$, Neal KR, et al. Relative importance of enterochromaffin cell hyperplasia, anxiety, and depression in postinfectious IBS. Gastroenterol 2003; 125(6):1651-1659.

23. LiuJ,CheyW,HallerE, etal.Low-FODMAPdietforirritablebowelsyndrome: What we know and what we haveyet to learn. Ann Rev Med2020; 71:303-314. doi: 10.1146/annurev-med-050218-013625.

24. James S, Fraser K, Young W, et al. Gut microbial metabolites and biochemical pathways involved in irritable bowel syndrome: Effects of diet and nutrition on the microbiome. J Nutr 2019; pii: nxz302. doi: 10.1093 jn/nxz302.

25. Bellini M, Tonarelli S, Nagy A, et al. Low FODMAP diet: Evidence, doubts, and hopes. Nutrients (2020) 12: 148. doi: 10.3390/nu12010148.

26. Barrett J, Gearry R, Muir J, et al. Dietary poorly absorbed, short-chain carbohydrates increase delivery of water and fermentable substrates to the proximal colon. Aliment Pharmacol Therapeut 2010; 31(8): 874 882. doi:10.1111/j.1365-2036.2010.04237.x.

27. McIntosh K, Reed D, Schneider T, et al. FODMAPs alter symptoms and the metabolome of patients with IBS: A randomised controlled trial. Gut 2016; 66: 1241-1251. doi: 10.1136/gutjnl-2015-311339.

28. Hustoft $\mathrm{T}$, Hausken $\mathrm{T}$, Ystad $\mathrm{S}$, et al. Effects of varying dietary content of fermentable short-chain carbohydrates on symptoms, fecal microenvironment, and cytokine profiles in patients with irritable bowel syndrome. Neurogastroenterol Motil 2016; 29(4):e12969. doi: $10.1111 / \mathrm{nmo} .12969$.

29. Huaman JW, Mego M, Manichanh C, et al. Effects of prebiotics vs a die low in FODMAPs in patients with functional gut disorders. Gastroentero 2018; 155(4): 1004-1007.

30. Simrén M, Barbara G, Flint $\mathrm{H}$, et al. Intestinal microbiota in functional bowel disorders: A Rome foundation report. Gut 2012; 62: 159-176. doi:10.1136/gutjnl-2012-302167

31. Sender R, Fuchs S, Milo R. Revised estimates for the number of human and bacteria cells in the body. PLoS Biol 2016; 14(8): e1002533.

32. Sekirov I, Russell S, Antunes L, et al. Gut microbiota in health and disease. Physiol Rev 2010; 90: 859-904. doi: 10.1152/physrev.00045.2009.

33. Chong CY, Bloomfield FH, O'Sullivan JM. Factors affecting gastrointestina microbiome development in neonates. Nutrients 2018; 10(3): 274. doi: 10.3390/nu10030274

34. Yiu JH, Dorweiler B, Woo CW. Interaction between gut microbiota and toll-like receptor: From immunity to metabolism. J Mol Med 2017; 95(1): $13-20$.

35. Tibbs TN, Lopez LR, Arthur JC. The influence of the microbiota on immune development, chronic inflammation, and cancer in the context of aging. Microb Cell 2019; 6(8): 324-334.

36. Iebba V, Totino V, Gagliardi A, et al. Eubiosis and dysbiosis: The two sides of the microbiota. New Microbiol 2016; 39(1): 1-12.

37. Jandhyala S. Role of the normal gut microbiota. World J Gastroenterol 2015; 21(29): 8787-8803. doi:10.3748/wjg.v21.i29.8787.

38. Rajilić-Stojanović M, Heilig HG, Tims S, et al. Long-term monitoring of the human intestinal microbiota composition. Environ Microbiol 2012; 15(4): 1146-1159.

39. Lozupone CA, Stombaugh JI, Gordon JI, et al. Diversity, stability and resilience of the human gut microbiota. Nat 2012; 489(7415): 220-230. doi: 10.1038/nature11550

40. Yassour M, Vatanen T, Siljander H, et al. Natural history of the infant gut 
microbiome and impact of antibiotic treatment on bacterial strain diversity and stability. Sci Translat Med 2016; 8(343): 343ra81.

41. Chassaing B, Aitken JD, Gewirtz AT, et al. Gut microbiota drives metabolic disease in immunologically altered mice. Adv Immunol 2012; 116P: 93-112. doi: 10.1016/B978-0-12-394300-2.00003-X

42. Joyce SA, Gahan CG. The gut microbiota and the metabolic health of the host. Curr Op Gastroenterol 2014; 30(2): 120-127. doi: 10.1097/ MOG.0000000000000039.

43. Lee WJ, Hase K. Gut microbiota-generated metabolites in animal health and disease. Nat Chem Biol 2014; 10(6): 416-424. doi: 10.1038/nchembio. 1535 .

44. Vazquez-Castellanos JF, Serrano-Villar S, Latorre A, et al. Altered metabolism of gut microbiota contributes to chronic immune activation in HIV-infected individuals. Mucosal Immunol 2015; 8(4): 760-772. doi: $10.1038 / \mathrm{mi} .2014 .107$.

45. Marchesi JR, Adams DH, Fava F, et al. The gut microbiota and host health: A new clinical frontier. Gut 2016; 65(2): 330-339. doi: 10.1136/gutjnl-2015-309990.

46. Rooks MG, and Garrett WS. Gut microbiota, metabolites and hos immunity. Nat Rev Immunol 2016; 16(6): 341-352. doi: 10.1038 nri.2016.42.

47. Rajilić-Stojanović M, Jonkers DM, Salonen A, et al. Intestinal microbiota and diet in IBS: Causes, consequences, or epiphenomena? Amer J Gastroenterol 2015; 110(2): 278.

48. Antonio N, Andrea T, Claudio T, et al. Digestive disorders and intestinal microbiota. Acta Biomed 2018; 89(Suppl 9): 47-51. doi: 10.23750/abm.v89i9-S.7912

49. Enck P, Mazurak N. Dysbiosis in functional bowel disorders. Ann Nutr Metab 2018; 72(4): 296-306. doi:10.1159/000488773

50. Lee LH, Letchumanan V, Khan TM, et al. IDDF2019-ABS-0322 Dissecting the gut and skin: Budding association between gut microbiome in the development to psoriasis? Gut 2019; 68: A41-A41.

51. Casén C, Vebø HC, Sekelja M, et al. Deviations in human gut microbiota: A novel diagnostic test for determining dysbiosis in patients with IBS or IBD. Aliment Pharmacol Ther 2015; 42(1): 7183. doi: $10.1111 /$ apt.13236.

52. Jeffery I, O'Toole P, Öhman L, et al. An irritable bowel syndrome subtype defined by species-specific alterations in faecal microbiota. Gut 2011; 61: 997-1006. doi:10.1136/gutjnl-2011-301501.

53. Kerckhoffs A, Samsom M, Rest M, et al. Lower Bifidobacteria counts in both duodenal mucosa-associated and fecal microbiota in irritable bowel syndrome patients. World J Gastroenterol 2009; 15: 2887. doi:10.3748/wjg. 15.2887 .

54. Jalanka-Tuovinen J, Salonen A, Nikkilä J, et al. Intestinal microbiota in healthy adults: Temporal analysis reveals individual and common core and relation to intestinal symptoms. PLoS One 2011; 6:e23035. doi: 10.1371/journal.pone.0023035.

55. Tap J, Derrien M, Törnblom H, et al. Identification of an intestinal microbiota signature associated with severity of irritable bowel syndrome. Gastroenterol 2017; 152:111-123. doi:10.1053/ j.gastro.2016.09.049.

56. Halkjær S, Christensen A, Lo B, et al. 914 - Fecal microbiota transplantation alters gut microbiota in patients with irritable bowel syndrome: Results from a randomized, double-blind placebo controlled study. Gastroenterol 2018; 154: S-181. doi: 10.1016/s00165085(18)31016-3.

57. Krogius-Kurikka L, Lyra A, Malinen E, et al. Microbial community analysis reveals high level phylogenetic alterations in the overall gastrointestinal microbiota of diarrhea-predominant irritable bowel syndrome sufferers. BMC Gastroenterol 2009; 9: 95. doi:10.1186/1471230x-9-95.

58. Crouzet L, Gaultier E, Del'Homme C, et al. The hypersensitivity to colonic distension of IBS patients can be transferred to rats through their fecal microbiota. Neurogastroenterol Motil 2013; 25:e272-e282. doi: $10.1111 /$ nmo.12103.

59. Böhn L, Störsrud S, Liljebo T, et al. Diet low in FODMAPs reduces symptoms of irritable bowel syndrome as well as traditional dietary advice: A randomized controlled trial. Gastroenterol 2015; 149: 13991407. doi: $10.1053 /$ j.gastro.2015.07.054.

60. Dolan R, Chey WD, Eswaran S. The role of diet in the management of irritable bowel syndrome:A focus on FODMAPs. Exp Rev Gastroentero Hepatol 2018;12(6): 607-615. doi: 10.1080/17474124.2018.1476138.

61. Staudacher H, Lomer M, Anderson J, et al. Fermentable carbohydrate restriction reduces luminal Bifidobacteria and gastrointestinal symptoms in patients with irritable bowel syndrome. J Nutr 2012; 142(8): 1510-1518. doi: 10.3945/jn.112.159285

62. Silk D, Davis A, Vulevic J, et al. Clinical trial: The effects of a transgalactooligosaccharide prebiotic on faecal microbiota and symptoms in irritable bowel syndrome. Aliment Pharmacol Ther 2009; 29: 508518. doi: 10.1111/j.1365-2036.2008.03911.x.

63. Maruo T, Sakamoto M, Ito C, et al. Adlercreutzia equolifaciens gen nov., sp. nov., an equol-producing bacterium isolated from human faeces, and emended description of the genus Eggerthella. Int J Syst
Evol Microbiol 2008; 58(5): 1221-1227.

64. Chumpitazi B, Cope J, Hollister E, et al. Randomised clinical trial: Gut microbiome biomarkers are associated with clinical response to a low FODMAP diet in children with the irritable bowel syndrome. Aliment Pharmacol Ther 2015; 42: 418-427. doi: 10.1111/apt.13286.

65. Valeur J, Småstuen M, Knudsen $\mathrm{T}$, et al. Exploring gut microbiota composition as an indicator of clinical response to dietary FODMAP restriction in patients with irritable bowel syndrome. Dig Dis Sci 2018; 63: 429-436. doi: 10.1007/s10620-017-4893-3.

66. Ringel-Kulka T, Choi C, Temas D, et al. Altered colonic bacterial fermentation as a potential pathophysiological factor in irritable bowel syndrome. Amer J Gastroenterol 2015; 110: 1339-1346. doi: 10.1038 ajg.2015.220

67. Ooi S, Correa D, Pak S. Probiotics, prebiotics, and low FODMAP diet for irritable bowel syndrome-What is the current evidence? Complement Therap Med 2019; 43: 73-80. doi: 10.1016/j.ctim.2019.01.010

68. Donohoe DR, Garge N, Zhang X, et al. The microbiome and butyrate regulate energy metabolism and autophagy in the mammalian colon. Cel Metabol 2011; 13(5): 517-526.

69. Moraes-Filho J, Quigley E. The intestinal microbiota and the role of probiotics in irritable bowel syndrome: A review. Arquivos de Gastroenterologia 2015; 52: 331-338. doi:10.1590 s0004-28032015000400015.

70. Venegas DP, Marjorie K, Landskron G, et al. Short chain fatty acids (SCFAs)-mediated gut epithelial and immune regulation and its relevance for inflammatory bowel diseases. Front Immunol 2019; 10: 277.

71. Corrêa-Oliveira R, Fachi JL, Vieira A, et al. Regulation of immune cell function by short-chain fatty acids. Clin Translat Immunol 2016; 5(4) e73.

72. Kajander K, Myllyluoma E, Rajilić-Stojanović M, et al. Clinical trial: Multispecies probiotic supplementation alleviates the symptoms of irritable bowel syndrome and stabilizes intestinal microbiota. Aliment Pharmacol Ther 2008; 27(1): 48-57.

73. Ducrotté P. Clinical trial: Lactobacillus plantarum 299v (DSM 9843) improves symptoms of irritable bowel syndrome. World J Gastroenterol 2012; 18: 4012. doi:10.3748/wjg.v18.i30.4012.

74. Ford A, Quigley E, Lacy B, et al. Efficacy of prebiotics, probiotics, and synbiotics in irritable bowel syndrome and chronic idiopathic constipation: systematic review and meta-analysis. Amer J Gastroentero 2014; 109: 1547-1561. doi: 10.1038/ajg.2014.202.

75. McKenzie, Y., Thompson, J., Gulia, P., et al. (2016). British Dietetic Association systematic review of systematic reviews and evidencebased practice guidelines for the use of probiotics in the management of irritable bowel syndrome in adults. Journal of Human Nutrition and Dietetics 2016; 29(5): 576-592.

76. Kajander K, Krogius-Kurikka L, Rinttilä T, et al. Effects of multispecies probiotic supplementation on intestinal microbiota in irritable bowel syndrome. Aliment Pharmacol Ther 2007; 26: 463-473. doi:10.1111/ j.1365-2036.2007.03391.x

77. Massi M, Ioan P, Budriesi R, et al. Effects of probiotic bacteria on gastrointestinal motility in guinea-pig isolated tissue. World Gastroenterol 2006; 12(37): 5987.

78. Kajander K, Hatakka K, Poussa T, et al. A probiotic mixture alleviates symptoms in irritable bowel syndrome patients: a controlled 6-month intervention. Aliment Pharmacol Therapeut 2005; 22: 387-394. doi:10.1111/j.1365-2036.2005.02579.x.

79. Lyra A, Krogius-Kurikka L, Nikkilä J, et al. Effect of a multispecies probiotic supplement on quantity of irritable bowel syndromerelated intestinal microbial phylotypes. BMC Gastroenterol 2010; 10 doi:10.1186/1471-230x-10-110

80. Hoskins LC, Agustines M, McKee WB, et al. Mucin degradation in human colon ecosystems. Isolation and properties of fecal strains that degrade $\mathrm{ABH}$ blood group antigens and oligosaccharides from mucin glycoproteins. J Clin Invest 1985; 75(3): 944-953.

81. Saulnier DM, Riehle K, Mistretta TA, et al. Gastrointestinal microbiome signatures of pediatric patients with irritable bowel syndrome. Gastroenterol 2011; 141(5): 1782-1791.

82. Brigidi P, Vitali B, Swennen E, et al. Effects of probiotic administration upon the composition and enzymatic activity of human fecal microbiota in patients with irritable bowel syndrome or functional diarrhea. Res Microbiol 2001; 152: 735-741, doi:10.1016/s0923-2508(01)01254-2.

83. Govender M, Choonara YE, Kumar P, et al. A review of the advancements in probiotic delivery: Conventional vs. non-conventional formulations for intestinal flora supplementation. Aaps PharmSciTech. 2014; 15(1): $29-43$.

84. O'Keeffe M, Lomer MC. Who should deliver the low FODMAP diet and what educational methods are optimal: A review. J Gastroenterol Hepatol 2017; 32: 23-26.

85. Staudacher HM. Nutritional, microbiological and psychosocial implications of the low FODMAP diet. J Gastroenterol Hepatol 2017; 32: 16-19. 